\title{
A Prática Docente de Educação de Jovens e Adultos no Sistema Prisional
}

\author{
Marcela Haupt Bessil \\ Universidade Federal do Rio Grande do Sul - Porto Alegre - RS - Brasil \\ Álvaro Roberto Crespo Merlo \\ Universidade Federal do Rio Grande do Sul - Porto Alegre - RS - Brasil
}

\begin{abstract}
Resumo
O presente artigo tem como objetivo compreender a dinâmica do prazer e sofrimento relacionando ao Trabalho de docentes de Educação de Jovens e Adultos nas prisões. Fundamenta-se teórica e metodologicamente na Psicodinâmica do Trabalho que aborda a saúde do trabalhador. Utilizou-se o método qualitativo, realizando entrevistas individuais, semi-estruturadas com dez professores de Educação de Jovens e Adultos que atuam na prisão. A análise dos resultados evidenciou que a organização dos estabelecimentos prisionais interfere diretamente nas atividades desses docentes. A relação com o aluno é vivenciada como um momento de prazer do trabalho, pois os docentes encontram o reconhecimento de sua atividade laborativa nesse momento, mas fazem referência ao preconceito que sofrem por parte da sociedade pelo fato de trabalharem no espaço prisional, dos familiares, dos colegas da rede regular de ensino e de outras áreas de atuação profissional e dentro do próprio sistema prisional. Concluindo, pensar o processo de trabalho implicar necessariamente uma reflexão sobre limites e possibilidades, mas principalmente sobre responsabilidades diante dessa população privada de liberdade.
\end{abstract}

Palavras-chave: Trabalho; Educação de Jovens e Adultos; Prisões.

\section{The Teaching Practice of Youth and Adult Education in the Prison System}

\begin{abstract}
The present article aims to understand the dynamics of pleasure and suffering relating to the work of youth and adult education teachers in prisons. It is based theoretically and methodologically in the Psychodynamics of Work that addresses the health of the worker. The qualitative method was used, performing individual interviews, semi-structured with ten teachers of Youth and Adult Education who work in prison. The analysis of the results showed that the organization of prisons interferes directly in the activities of these teachers. The relationship with the student is experienced as a moment of work pleasure, since the teachers find the recognition of their work activity at that moment, but they make reference to the prejudice that suffer from the society by the fact of working in the prisional space, the relatives, the colleagues of the regular network of education and of other areas of professional performance and within the own prison system. In conclusion, thinking about the work process necessarily involves a reflection on limits and possibilities, but mainly on responsibilities towards this population deprived of freedom.
\end{abstract}

Keywords: Labor; Youth and Adult Education; Prisons.

\section{La práctica docente de educación de jóvenes y adultos en el sistema carcelario}

\begin{abstract}
Resumen
El presente artículo tiene como objetivo comprender la dinámica del placer y sufrimiento relacionando al trabajo de docentes de Educación de Jóvenes y Adultos en las cárceles. Se fundamenta teórica y metodológicamente en la Psicodinámica del Trabajo que aborda la salud del trabajador. Se utilizó el método cualitativo, realizando entrevistas individuales, semi-estructuradas con diez profesores de Educación de Jóvenes y Adultos que actúan en la cárcel. El análisis de los resultados evidenció que la organización de los centros penitenciarios interfiere directamente en las actividades de estos docentes. La relación con el alumno es vivenciada como un momento de placer del trabajo, pues los docentes encuentran el reconocimiento de su actividad laborativa en ese momento pero, hacen referencia al prejuicio que sufren por parte de la sociedad por el hecho de trabajar en el espacio prisional, de los familiares, de los colegas de la red regular de enseñanza y de otras áreas de actuación profesional y dentro del propio sistema penitenciario. Concluyendo, pensar en el proceso de trabajo implicar necesariamente una reflexión sobre límites y posibilidades, pero principalmente sobre responsabilidades frente a esa población privada de libertad.
\end{abstract}

Palabras clave: Trabajo; Educación de Jóvenes y Adultos; Prisiones. 


\section{Introdução}

Esta pesquisa se propõe a discutir sobre o conteúdo do prazer/sofrimento da prática laborativa dos docentes de Educação de Jovens e Adultos (EJA) no Sistema Prisional. Apresenta como problema de pesquisa a pergunta: como a complexidade das situações vividas pelos docentes de EJA no Sistema Prisional repercute no prazer/sofrimento mental?

A partir desse problema de pesquisa foram abordadas as questões teóricas do trabalho, da prática docentes e suas peculiaridades no sistema prisional. A teoria e a metodologia utilizada foram a psicodinâmica do trabalho. A análise dos dados foi estabelecida por meio dos conteúdos das falas trazidas nas entrevistas individuais.

O campo de pesquisa estabelecido foi o contexto do sistema prisional, e os sujeitos foram os professores que atuam na área de Educação de Jovens em Adultos dentro das Penitenciárias do Rio Grande do Sul. No entanto, são servidores da Secretaria de Educação do Estado. Dessa forma, o eixo de análise centraliza-se no trabalho docente de Educação de Jovens e Adultos Privados de Liberdade que por questões didáticas foram divididos em três grandes áreas: sistema prisional, educação e trabalho.

A educação é um direito garantido pela Constituição Federal de 1988. Logo em seu art. 6º , o documento jurídico mais importante do nosso país diz que a educação - juntamente com a moradia, o trabalho, o lazer, a saúde, entre outros - é um direito social. Ou seja, não é um favor do Estado para as pessoas, pelo contrário, é um direito de cidadania. Mais à frente, o artigo 205 da Constituição (1988) afirma: "A educação, direito de todos e dever do Estado e da família, será promovida e incentivada com a colaboração da sociedade, visando ao pleno desenvolvimento da pessoa, seu preparo para o exercício da cidadania e sua qualificação para o trabalho". Aqui fica explícito o dever do Estado e o direito de todas as pessoas, sem qualquer distinção, com relação à educação.

A Lei de Execuções Penais (LEP), de 1976, introduz a obrigatoriedade de o Estado oferecer a assistência necessária para os indivíduos que se encontram presos. Conforme o Artigo 10, "A assistência ao preso e ao internado é dever do Estado, objetivando prevenir o crime e orientar o retorno à convivência em sociedade" (Moreira, 2007, p. 34). O Artigo 11 da LEP especifica quais são as obrigatoriedades do Estado para com o preso: material, saúde, jurídica, educacional, social e religiosa.

"Constatamos assim, a obrigação legal de o Poder Público, operador do sistema penal, oferecer condições que possam fazer do cumprimento da pena uma verdadeira oportunidade de socialização daqueles que passam pela situação de privação de liberdade" (Moreira, 2007, p. 34).

Mas para que a educação seja ofertada no sistema prisional é preciso que existam trabalhadores para desempenhar a atividade de docência dentro desses espaços. Então, nesta pesquisa buscou-se centrar a discussão sobre essa prática docente no contexto prisional através do olhar da Psicodinâmica do Trabalho (PdT).
A Organização Internacional do Trabalho (OIT) declara que o trabalhador docente ocupa um lugar fundamental na sociedade, pois esta categoria contribui para a formação pessoal e profissional dos seres humanos (OIT, 1984). Segundo Perez (2012), a literatura existente relacionando a saúde e o trabalho docente ainda é escassa, especialmente se compararmos com outras categorias de trabalhadores a qual o trabalho é considerado potencialmente degradante. Entretanto, tem se observado um crescente desenvolvimento de pesquisas sobre a categoria de professores. Contudo, encontramos muitos estudos sobre o trabalho docente na área da educação básica, sendo pouquíssimos os estudos sobre docentes de Educação de jovens e Adultos Privados de Liberdade.

É relevante abordar as questões subjetivas que envolvem a prática docente no Sistema Prisional, pois existem peculiaridades na realização da prática de Educação de Jovens e Adultos nesse contexto específico. Ao mesmo tempo, é importante investigar a dinâmica prazer/sofrimento vivida pelos docentes de EJA no sistema prisional com relação a sua prática laborativa. Assim, por meio deste estudo temos a oportunidade de refletir sobre o trabalho do educador no contexto prisional e propor ações de saúde do trabalhador específicas para essa categoria profissional.

\section{Sistema Prisional}

O Sistema Prisional Brasileiro tem sido desacreditado em relação ao objetivo para o qual foi criado, que é de ressocializar o indivíduo. Podemos perceber isso através das notícias veiculadas pela mídia que mostram um sistema superlotado e deficiente de recursos materiais e humanos, em que, com frequência, a Comissão de Direitos Humanos tem que interferir em função da falta de condições dignas para os que ali se encontram cumprindo pena restritiva de liberdade. Vale destacar que "a ideia de execução de pena privativa de liberdade deve ter por base o princípio da humanidade e qualquer modalidade de punição desnecessária, cruel ou degradante será de natureza desumana e contra o princípio da legalidade" (Assis, 2007, p. 75).

Segundo Tavares \& Menandro (2004), as prisões brasileiras funcionam como mecanismos de oficialização da exclusão já existente sobre alguns indivíduos, como um atestado de exclusão com firma reconhecida. Dizem isso não só considerando o estado atual de precariedade das prisões, mas também o estado de precariedade em que se encontram os indivíduos antes do encarceramento - em sua maioria, provenientes de grupos marcados pela exclusão.

As prisões, no decorrer dos anos, estão cada vez mais lotadas, as punições se tornando cada vez mais uma retribuição pelo mal causado por este indivíduo em função do delito cometido. A justiça penal, quando sentencia a pena, não só passa a privar de liberdade os condenados, mas também de todos seus direitos contidos na Constituição Federal, pela deficiência de condições humanas, materiais, pela falta de funcionários na defensoria jurídica, nos servi- 
ços sociais, na psicologia e no atendimento à saúde (Assis, 2007).

\section{Educação no Sistema Prisional}

Punir e reabilitar são os grandes desafios do nosso sistema prisional. Português (2001), ao analisar as possibilidades e contradições da inserção da educação escolar nos programas de reabilitações das prisões, afirma que esse dilema se faz necessário, pois essa dupla finalidade que se espera do encarceramento evidencia contradições que fazem parte da organização das prisões.

Sendo assim, atribui-se um caráter educativo, ou meIhor, reeducativo à pena. Mas os imperativos da segurança e disciplina acabam se sobrepondo em relação à educação desses indivíduos que lá se encontram. Isso traz consequências, pois o sujeito que retorna à sociedade não é aquele que a sociedade espera que volte - reeducado ou ressocializado (Moreira, 2007). Dessa forma, a segurança pode ser entendida como a barreira física que impede o direito de ir e vir do indivíduo, como sinônimo de cerceamento da liberdade e isolamento com relação à sociedade. Já a disciplina é a obediência com relação à sentença e condenação, ou seja, obediência hierárquica, acatamento de ordens, respeito aos companheiros e cumprimento das obrigações impostas.

Silva (2006) se refere à existência da identificação de limites e de possibilidades da Educação de Jovens e Adultos na prática docente com presos. Uma das limitações é que a formação inicial do docente não atende às necessidades de ordem teórico-prática para os docentes atuarem na Educação de Jovens e Adultos, mas, por outro lado, a formação continuada tem sido caracterizada por encontros denominados de "capacitações", que, quando acontecem, referem-se a aspectos gerais da educação. E que quando são específicos da Educação de Jovens e Adultos não trazem quase nenhuma contribuição para o(a) professor(a) que trabalha na escola na prisão.

\section{Educação no Sistema Prisional no Rio Grande do Sul}

A Secretaria de Educação, desde o ano de 1970, oferece atendimento ao apenado, com especial ênfase em classes de alfabetização e oferta de exames supletivos que ocorrem sob coordenação da Superintendência dos Serviços Penitenciários no Rio Grande do Sul (SUSEPE), através do Departamento de Tratamento penal (DTP). Essa assistência segue o que é previsto na Lei de Execuções Penais (LEP) (Mello \& Crady, 2010).

Atualmente o sistema prisional no Rio Grande do Sul conta com 11 Núcleos Estaduais de Educação de Jovens e Adultos (NEEJAs) funcionando como escolas regulares. $O$ Conselho Estadual de Educação é o órgão que autoriza a implantação dos núcleos educacionais, que fazem parte do sistema estadual de educação e estão sob a responsabilidade da Secretaria Estadual de Educação, embora ocorram nas dependências da SUSEPE (Mello \& Crady, 2010).
O quadro de docentes que atuam nas prisões do Rio Grande do Sul é procedente da parceria entre as Secretarias de Segurança Pública com as Secretarias Estaduais e Municipais de Educação (Mello \& Crady, 2010).

\section{Trabalho}

O conflito central da psicologia do trabalho constitui-se no conflito entre a organização do trabalho e o funcionamento psíquico. O núcleo da clínica do trabalho definiu a psicopatologia do trabalho como a análise do sofrimento psíquico resultante do confronto dos homens com a organização do trabalho. Outra definição mais atualizada seria "analise psicodinâmica dos processos intersubjetivos mobilizados pelas situações de trabalho" (Lancman \& Sznelwar, 2011).

Existe uma dupla polaridade do trabalho: se por um lado é fonte de desgaste e sofrimento, ele é também atividade criativa e meio de sublimação. Ele pode ser observado de acordo com as experiências do sujeito no trabalho e das diversas formas de desadaptação provocada pela saturação dos mecanismos de defesa (Bendassolli \& Soboll, 2011).

Sendo assim, trabalhar é preencher a lacuna existente entre o prescrito e o efetivo. Faz-se necessário repetir que o trabalho se define como aquilo que o sujeito deve acrescentar às prescrições para atingir os objetivos que lhe são confiados; ou ainda o que ele deve dar de si mesmo para fazer frente ao que não funciona quando ele segue escrupulosamente a execução das prescrições. Essa lacuna entre o prescrito e o efetivo, no trabalho, nunca é definitivamente preenchida. Sobrevêm sempre em situações de trabalho, dificuldades e incidentes imprevistos (Dejours, 2012).

\section{Método}

A metodologia utilizada na realização desta pesquisa se baseou nos pressupostos teóricos e práticos da Psicodinâmica do Trabalho ( $\mathrm{PdT})$. Considera-se um estudo teórico e metodológico da Psicodinâmica do trabalho, pois toda a fundamentação para a descrição e análise dos resultados foi guiada pelos passos e procedimentos propostos pela PdT.

A pesquisa propriamente dita é subdividida em quatro momentos: Análise da demanda (levantamento da questão sobre os trabalhadores), Análise do material de pesquisa (revisão bibliográfica), Observação clínica (grupos e/ou entrevistas) e Interpretação: "o material da interpretação, em psicodinâmica do trabalho, é assim, uma observação comentada" (Dejours, 2004, p. 121).

Optou-se por fazer entrevistas individuais, semiestruturadas com os docentes, as quais foram realizadas nos dias em que os professores se encontram para participarem das reuniões pedagógicas. Nesse momento, foi abordada a questão da prática docente de EJA no Sistema prisional através dos seguintes questionamentos: Como entrou para o EJA no sistema Prisional? Por que escolheu trabalhar nesse local? Pretende continuar atuando nesse contexto? Exerce outra 
atividade além da docência nesse local? O que percebe de diferente do EJA no sistema prisional do EJA extra-muros? Como se sente em trabalhar em um estabelecimento prisional? Como é a relação com os colegas? Como é a relação com os familiares? Como é a relação com os alunos? O que tu gostas no teu trabalho? O que tu não gostas no teu trabalho? Como se sente frente a essas situações? Quais as maiores dificuldades encontradas no teu trabalho? Com quem você conversa sobre essas situações? O que achas que deveria mudar no seu trabalho ou na instituição onde trabalhas?

Os conteúdos trazidos nas falas dos entrevistados foram analisados através da teoria da Psicodinâmica do TrabaIho. Nesse momento, a análise do conteúdo está interessada nas explanações verbais dos participantes sobre o trabalho. Para pesquisar a relação entre saúde e trabalho são utilizados instrumentos e técnicas baseadas na psicodinâmica do trabaIho, cujo foco está na palavra do trabalhador, no seu discurso e como isso se articula coletivamente (Baierle \& Merlo, 2008). Dessa maneira, o uso de entrevistas também pode ser uma maneira proveitosa e interessantes para aprofundar questões referentes à relação entre trabalho e sofrimento.

Esta pesquisa foi encaminhada e aprovada pelo Comitê de Ética da Universidade Federal do Rio Grande do Sul. Depois foi encaminhada para a Escola Penitenciária da SUSEPE para a aprovação e autorização de realização.

As entrevistas foram operacionalizadas em local identificado com o trabalho, dentro de um dos estabelecimentos prisionais, onde os docentes se encontram semanal- mente para a realização do "Encontro Pedagógico". A sala disponibilizada foi a da biblioteca localizada ao lado da sala de reuniões dos professores. As entrevistas foram gravadas por meio de gravador digital e posteriormente, transcritas.

Não há como objetivar os sentimentos de prazer e sofrimento, já que esses são essencialmente subjetivos. Por isso, tais dados devem ser percebidos pelo pesquisador que também tem sua subjetividade envolvida (Perez, 2012).

O objetivo é dar forma ao que, para o pesquisador, em seu contato com os trabalhadores, surge como surpreendente, espantoso, incompreensível, doloroso, angustiante, agressivo, em relação à experiência que ele tem com outros coletivos e que advêm de sua prática clínica, individual, psiquiátrica, em psicopatologia do trabalho em outras áreas. Em outros termos, experiência em relação ao conjunto do corpus psicopatológico (Dejours, 2004, p.124).

No total, foram realizadas entrevistas com 10 docentes nos dias em que acontecem as reuniões pedagógicas do Núcleo Educacional. Essas reuniões ocorrem nos mesmos dias em que são realizadas as visitas de familiares aos apenados nas casas prisionais, por isso nesses dias não são ministradas aulas.

\section{Resultado e Discussão}

A Psicodinâmica do Trabalho tem como objetivo analisar estratégias de mediação do sofrimento utilizadas

Tabela 1. Objetivo geral, objetivos específicos e eixos temáticos da pesquisa

\begin{tabular}{|c|c|c|}
\hline Objetivo Geral & Objetivos Específicos & Eixos Temáticos \\
\hline \multirow[t]{3}{*}{$\begin{array}{l}\text { Compreender a dinâmica } \\
\text { Prazer-sofrimento no } \\
\text { trabalho de docentes } \\
\text { de Educação de Jovens } \\
\text { e Adultos Privados de } \\
\text { Liberdade }\end{array}$} & $\begin{array}{l}\text { Investigar a implicação da organização do } \\
\text { trabalho na prática docente de Educação } \\
\text { de Jovens e Adultos no sistema prisional } \\
\text { no processo de subjetivação de seus } \\
\text { integrantes. }\end{array}$ & $\begin{array}{l}\text { Organização do Trabalho } \\
\text { - Contextualizando a sala de aula dentro do } \\
\text { sistema prisional } \\
\text { - Especificidades sobre a prática docente no } \\
\text { Sistema Prisional } \\
\text { - Reconhecimento } \\
\text { - Rotina }\end{array}$ \\
\hline & $\begin{array}{l}\text { Identificar as estratégias individuais e } \\
\text { coletivas construídas pelos docentes } \\
\text { para o enfrentamento do cotidiano no } \\
\text { trabalho com Jovens e Adultos Privados } \\
\text { de Liberdade }\end{array}$ & $\begin{array}{l}\text { Estratégias } \\
\text { - Sentido, identidade e o trabalho do docente } \\
\text { de EJA no Sistema Prisional } \\
\text { - Planejamento e preparação das aulas } \\
\text { - Em sala (Cela) de aula } \\
\text { - Prazer e sofrimento no Trabalho docente } \\
\text { de EJA no Sistema Prisional } \\
\text { - Reuniões Pedagógicas }\end{array}$ \\
\hline & $\begin{array}{l}\text { Mapear o desejo que envolve essa } \\
\text { prática docente de Educação de Jovens } \\
\text { e Adultos no Sistema Prisional. }\end{array}$ & $\begin{array}{l}\text { Prática Docente } \\
\text { - Entrada no Sistema Prisional } \\
\text { - Capacitações } \\
\text { - Outras atividades além docência intra- } \\
\text { muros } \\
\text { - O que espera do seu trabalho no sistema } \\
\text { prisional } \\
\text { - Saúde }\end{array}$ \\
\hline
\end{tabular}


pelos trabalhadores na busca de saúde, o que isso acontece por meio da interação entre o sujeito e as dimensões do contexto de produção de bens e serviços. Para essa teoria, o importante é a compreensão de como os trabalhadores mantêm o equilíbrio psíquico mesmo quando submetidos a condições de trabalho desestruturantes (Facas, Machado, \& Mendes, 2012; Merlo, 2006; Ferreira \& Mendes, 2003; Dejours, 2003).

Precisamos refletir a respeito de que, as pessoas privadas de liberdade têm direito a assistência à saúde e à educação. No entanto, para que esses direitos sejam respeitados é preciso profissionais atuando dentro do sistema prisional para executar as diferentes atividades que devem ser oportunizadas. E esses profissionais sofrem inúmeros impactos com relação a sua saúde e sua prática devido ao encarceramento.

Neste estudo buscou-se analisar a questão do trabaIho em relação ao prazer e ao sofrimento que envolvem a prática docente no sistema prisional. Na Tabela 1 abaixo são descritos o objetivo geral, os objetivos específicos e os eixos temáticos da pesquisa.

Conforme o que foi dito pelos entrevistados, percebe-se investimento físico e mental feito pelos docentes para desempenhar as suas atividades laborativas dentro das instituições prisionais, assim como lidar com as intercorrências que acontecem dentro das casas prisionais também faz parte do trabalho do professor. Isso pode ser observado no trecho em que o entrevistado fala sobre as diferenças que percebe com relação a sua atuação profissional dentro do sistema prisional no que se refere às escolas extra-muros:

É tudo diferente. Porque uma coisa é uma escola regular, outra coisa é uma escola dentro do sistema prisional, desde as características, as condições da casa, as características das pessoas, aquilo que é oferecido para elas, o contexto que elas estão. É tudo diferente, é uma metodologia diferente, é um olhar diferente.

Essas diferenças entre o trabalho realizado pelo docente na rede regular de ensino do trabalho realizado dentro das instituições prisionais vão para além do espaço físico, envolvem questões sobre recursos materiais, recursos metodológicos, rotina, acompanhamento, rotatividade de alunos, deslocamento dos alunos até o local de sala de aula entre outros.

Os docentes levantaram uma questão sobre a organização do trabalho dos professores dentro das casas prisionais, que é a condução dos alunos/detentos até a sala de aula. Cada casa prisional tem suas particularidades com relação ao procedimento de deslocamentos dos detentos até a sala de aula. Em algumas instituições, os detentos são trazidos um a um de suas galerias até a sala de aula e o mesmo procedimento se repete ao término da aula. Já em outras instituições prisionais, todos os detentos da mesma galeria são chamados juntos e se deslocam assim, sob a vigilância dos agentes de segurança até o espaço de sala de aula e o mesmo acontece no retorno. Mas para que esses alunos sejam chamados/acompanhados pelos servidores da segurança é preciso que os professores entreguem a lista com os nomes dos alunos que estão frequentando as aulas, a qual é criada a partir da manifestação do desejo por parte do indivíduo que se encontra privado de liberdade para ter seu nome incluído no setor educacional. Este setor repassa os nomes para a liberação da área da segurança, e assim são formadas as turmas de acordo coma etapa de escolarização de cada aluno. Com o início das aulas, os próprios alunos vão trazendo novos nomes para frequentar as aulas. Então, se reinicia o processo burocrático explicado anteriormente.

As questões sobre os deslocamentos dos alunos para chegarem até a sala de aula são trazidas pelos docentes como algo que traz sofrimento no trabalho:

Eu não gosto do sistema aqui às vezes, por exemplo, é... O retirar eles de dentro da sala de aula é mais difícil. Lá fora tem aquele horário, eles saem da sala de aula e aqui não, tu depende de alguém para retirar eles.

O espaço escolar na prisão assume características próprias à instituição escolar e sua cultura, com espaços, tempos e regularidades característicos dessa instituição, obviamente marcados pelo fato de estar inserida na instituição prisional, o que marca as atividades nela desenvolvidas (Santos, 2002; Penna, 2003). Dessa forma, a escola na prisão apresenta-se como local diferenciado, com discursos e regularidades próprios, além de constituir-se claramente como um valor.

Aqui eu tô lidando com pessoas que estão vamos dizer assim, privadas de liberdade, pessoas que te respeitam como professor, pessoas que precisam de alguém.

Com relação ao espaço físico, algumas salas de aula apresentam grades para dividir o espaço físico entre o professor e os alunos. Essa barreira física com relação ao contato com os alunos mobiliza os docentes de EJA no sistema prisional: “... a única diferença é a grade, porque eu me vejo como a professora e eles os alunos”.

A prática educativa tem suas especificidades de acordo com o contexto no qual se desenvolve. Quando a prática educativa acontece no ambiente prisional, a escola tem as suas regras e procedimentos submetidos às regras e procedimentos do estabelecimento prisional. "A escola na prisão encontra-se submetida à lógica carcerária” (Penna, 2006, p. 33), conforme referem diferentes pesquisas, dentre as quais se destacam Portugues (2001), Santos (2002) e Penna (2003). Por um lado, as rígidas normas e procedimentos oriundos da necessidade de segurança, ordem interna e disciplina das unidades que prescrevem as atividades escolares; do outro lado, a atividade docente.

Os docentes de EJA no sistema prisional percebem essa diferenciação com relação a sua atividade docente no Sistema Prisional de sua atividade docente extra-muros (na rede formal de ensino), como podemos evidenciar nas se- 
guintes falas: "Lá fora, os professores ficam reclamando que os alunos trazem muita coisa, da internet e tal. Aqui dentro não. Ao contrário, a gente faz um esforço gigante para sair daqui”.

$\mathrm{Na}$ rede regular de ensino tem se estudado muito sobre a evasão escolar, já na área educacional no sistema prisional os docentes se referem muito sobre a rotatividade dos alunos: "A diferença daqui é que a gente nunca tem a mesma turma de um mês para o outro. Ou são transferidos, desistem, não vão mais, aí no mês seguinte entra mais alunos novos".

Essa rotatividade gera impactos com relação à organização e planejamento das atividades dos docentes: "As dificuldades... é a questão da rotatividade dos alunos nas cadeias, isso atrapalha o trabalho".

Os docentes também sabem que os apenados que procuram o setor educacional têm a remissão de pena pelos dias estudados de acordo com a Lei Federal № 12.433 , do dia 30 de junho de 2011, em que a cada 12 horas de estudo obtêm-se a remição de um dia de pena. "Eles não são bobos, eles muitas vezes vêm para a sala de aula para adquirir (alguma coisa) ou ter alguma vantagem. Eles não vêm porque realmente querem aprender, não. Eles querem vir para a remição".

Ainda sobre as diferenças, percebe-se a relação com a segurança dos estabelecimentos prisionais. São os profissionais da segurança que sinalizam se naquele dia vai poder ter aula ou não e avaliam os recursos a serem utilizados. Por um lado, essas ações produzem sofrimento (ao passo que os docentes estão sendo avaliados), por outro lado, produz sentimentos de segurança e apoio na retaguarda para a realização das aulas.

A relação com a equipe de segurança gera esses sentimentos de ambivalência, ora de cuidado e/ou apoio, ora de avaliação, de estar sendo vigiado. Estar realizando um trabalho dentro do sistema prisional no qual a segurança está sempre alerta com a conduta dos que lá se encontram cumprindo medida restritiva de liberdade gera mobilizações subjetivas nos trabalhadores de que eles possam estar sendo vigiados.

Alguns trabalhadores acreditam que esse "estar sendo vigiado" está relacionado com a manutenção da segurança no estabelecimento prisional. E que essa atitude buscaria evitar o envolvimento dos trabalhadores do sistema prisional com os que se encontram ou já estiveram cumprindo medida restritiva de liberdade, conforme relato abaixo:

...nós somos um pouco cobrados, ninguém me cobra, mas nós somos vigiados e se eu tenho um contato com o preso aqui e eu mantenho na rua, nós sabemos que existe uma... um monitoramento... e aí eles sabem, qual é a relação do professor com o fulano? É o próprio sistema né. Se isso acontece ou não acontece, pode até ser coisa da minha cabeça, mas eu sempre me cuidei muito para não deixar criar vínculo ou que a guarda ou o sistema saiba "o professor tá tendo contato com aquele tal".
Os recursos materiais a serem utilizados em sala de aula também passam pela avaliação da segurança das casas prisionais, como relatam os docentes:

... nós somos bastante limitados com o material né, na questão de vídeos, DVD, qualquer coisa que a gente quer levar primeiro tem que passar previamente pela segurança e a segurança vai examinar esse material e só depois vai liberar.

Essa seleção de manterias proporciona a criatividade dos docentes para manter os alunos interessados pelos conteúdos, conforme um entrevistado nos relata:

... no início foi uma frustração porque eu preparava coisas para chegar na sala de aula e fazer de uma determinada forma e tinha a segurança. Não podia levar determinadas coisas. Então eu tinha que me transformar naquele momento, ter uma outra criatividade para ver como poderia trabalhar determinados conteúdos naquele espaço que era diferente.

Scarfò (2002) coloca que o professor atuante no sistema prisional se reveste como um profissional que transmite conhecimentos específicos, mas também contribui com a elaboração de um projeto de vida que se constrói pelo diálogo, pela sensibilidade aos problemas sociais, pela disponibilidade para a escuta. Em relação às estratégias metodológicas, elas estão vinculadas às da educação de jovens e adultos, respeitando seus saberes da vida, expectativas, visões de mundo, mas há que se respeitar as regras específicas do contexto, ou seja, recursos que possam trazer qualquer tipo de risco em relação à segurança, não são permitidos. Dessa forma, todo o material é examinado pelo setor de segurança, antes de sua utilização (Onofre, 2012).

A pesquisa dentro da sala de aula da prisão acontece de forma diferenciada, o professor tem que definir o que os alunos vão pesquisar. Mas também tem que levar os recursos pelos quais os alunos vão realizar a pesquisa, como livros, revistas, jornais, revistas em quadrinhos entre outros, sempre depois de ter passado pela equipe de segurança da casa e ser autorizado.

Seguindo nessa perspectiva, a reflexão sobre o papel do profissional que assume as salas de aula nas prisões nos leva a desafios no sentido de equacionar problemas que também existem "fora dos muros", como por exemplo: a baixa remuneração e precariedade das condições de trabalho (Onofre, 2012). Na atividade docente em instituições prisionais os docentes também sentem prazer por exercer sua atividade profissional:

Então eu gosto, eu não vim para cá para me aposentar como existem algumas falas "ai, não vejo a hora de sair daqui", mas eu gosto do meu trabalho e eu sinto que eu estou ajudando eles, da forma deles, mas há um carinho e eu tenho um retorno, então... 
Nessa direção, tem havido questionamento intenso - social e acadêmico - em torno do papel da educação, da escola e dos professores na construção da sociedade, e isto sugere, no dizer de Alarcão (2001), uma espécie de reinvenção da profissão docente, onde as expectativas depositadas no professor são diferentes daquelas que vigoravam num passado recente. Há que se pensar em um profissional acolhedor da diversidade, aberto à inovação, comprometido com o sucesso da aprendizagem e solidário com as características e dificuldades de seus alunos. Para tanto, é importante que esse profissional tenha capacidade de articular os conteúdos curriculares aos conhecimentos pedagógicos, que garanta a efetivação de projetos interdisciplinares, trabalhe em equipe de maneira reflexiva, que improvise com criatividade e se comprometa com a gestão de seu desenvolvimento profissional com autonomia (Rego \& Mello, 2002).

Na fala de um dos entrevistados aparece a ambivalência com relação ao trabalho. Ao mesmo tempo em que é frustrante com relação às limitações por ser realizado em um espaço de confinamento, também é prazeroso, pois os profissionais da educação sentem sua atividade profissional valorizada.

... não, não é fácil para ninguém... O sistema penitenciário é, em qualquer setor, ele é muito restrito, limita demais. $E$ a gente vê que às vezes parece que o trabalho da gente é frustrante. Mas, ao mesmo tempo, tu vê que é necessário, ele tá agindo de uma forma necessária e ajuda. Parece que a educação ajuda todo mundo, parece que integra todo mundo, um pouco ali e outra aqui e a gente consegue fazer alguma coisa.

Outro aspecto recorrente a todo o momento na fala dos entrevistados, é a questão da disciplina existente por parte dos alunos dentro do presídio, disciplina que segundo os relatos dos entrevistados não é vista no ensino regular, outro motivo que por si só já garante a satisfação de trabaIhar dentro de uma unidade penal.

O princípio fundamental da educação escolar, que é por essência transformador, aponta o tempo-espaço da escola como possibilidade, enquanto a cultura prisional, caracterizada pela repressão, pela ordem e disciplina, visando adaptar o indivíduo ao cárcere, aponta para um tempo-espaço que determina mecanicamente as ações dos indivíduos (Onofre, 2012).

... mas como a gente sabe que o sistema, a nossa sociedade tem como objetivo excluir né, e isso é uma forma de exclusão. Tu pega essa criança, esse jovem que não se adapta ao nosso sistema e exclui. Não é por aí, porque tu vai simplesmente só tirar dos teus olhos, mas o problema continua, tá ali, só para não ver, porque tá preso, mas o dia que ele sair ...

Esse relato corrobora a ideia de que as prisões brasileiras funcionam como mecanismos de oficialização da exclusão que já marca a vida dos detentos, uma vez que é grande o estado de precariedade em que eles se encontram antes do encarceramento - o que se evidencia, também, na experiência de fracasso escolar acumulada por eles.

A realização das atividades profissionais dentro do sistema prisional gera impacto na família dos docentes. Os medos, os anseios do que pode acontecer dentro desses locais são vivenciados constantemente tanto pelos trabaIhadores como por seus entes queridos, bem como há o questionamento a respeito do porquê continuar exercendo a docência no sistema prisional e se existe medo durante a jornada de trabalho, que como relata um dos entrevistados, é frequente:

...se a gente tem medo de ficar ali com eles e eu digo "não, são pessoas, seres humanos iguais a nós", "mas tu não tem medo do que ele fez?", "não, isso é um dos nossos propósitos, não. Saber o porquê cada um está ali, essa não é a nossa função. Nossa função é ensiná-los".

E mesmo quando os alunos querem falar sobre os que os trouxe até esse local, contar suas histórias não é aberto espaço. Essa não permissão para falar sobre os delitos é o que torna viável o trabalho desses docentes. $O$ relato abaixo descreve como é necessária a negação do delito para que esse docente consiga exercer sua atividade laborativa:

... o objetivo dos professores aqui é só a educação, então o que vocês fizeram, porque estão aqui, isso não nos interessa. E eu não sei por que os meus alunos estão lá, eu não quero saber, eu não tenho curiosidade nenhuma em saber. Isso é o que eu deixo bem claro para eles no momento em que vão para a minha turma, "para mim vocês são alunos iguaizinhos aos que eu já trabalhei, então eu não quero saber". A gente não conversa esse tipo de coisa na sala de aula, é só educação.

Nesses relatos podemos observar o mecanismo de defesa da negação utilizado como recurso para a realização das tarefas, pois o entrevistado relata que não tem como objetivo saber o que cada um fez para estar ali cumprindo medida restritiva de liberdade. Para isso focam no ensino como argumento para não pensar sobre o que trouxe cada pessoa ao sistema prisional. "Tu te blinda, sabe? Tu cria, não é uma carapuça, mas tu te blinda de muitas coisas que acontecem".

Esse distanciamento que envolve o trabalhador do sistema prisional também faz com que ele não tente conversar sobre o seu trabalho com outras pessoas que não exerçam suas atividades no mesmo meio, como podemos perceber no relato a seguir sobre o seu trabalho com outras pessoas fora do sistema prisional:

Geralmente, a gente tem que se, digamos "bitolar" no que pode e no que não pode falar aqui dentro, porque assim como a gente não pode trazer nada aqui para dentro, a gente não pode levar nada para fora, porque é um trabalho diferenciado. 
E há a tentativa de os professores dividirem os acontecimentos que os mobilizaram durante o trabalho com os familiares, mas acabam não encontrando espaço para isso. A maioria dos professores relatou não encontrar amparo com relação aos seus anseios nas conversas em família, que prefere se manter distante do cotidiano do sistema prisional. Isso gera sofrimentos nos docentes que acabam encontrando espaço para compartilhar essas questões com os colegas de trabalho nas reuniões pedagógicas.

No início quando eu comecei, eu comentava muito em casa. Ai um belo dia minha esposa disse "Para! Eu não quero mais ouvir". Então eu comecei a assimilar coisas e a criar um limite, aquilo que eu ouço das histórias escabrosas que a gente ouve aqui. Filtro e passa.

Os professores executam um trabalho onde sabem que estão sendo observados e avaliados por seus alunos, mas no espaço prisional, os professores também estão sendo observados pelos seus colegas de trabalho que exercem outras atividades dentro dos presídios. Além disso, as suas atividades de trabalhado são avaliadas e autorizadas ou não por outros profissionais que atuam no sistema prisional. Com isso, acabam levando essa possibilidade de serem observados também fora de seus locais de trabalho, ou seja, na vida privada.

\section{Considerações Finais}

O ambiente prisional é complexo, com características específicas. Assim, para um trabalho efetivo são necessários saberes, habilidades e competências próprias. São essas peculiaridades que envolvem o prazer e o sofrimento no trabalho na prática docente de Educação de Jovens e Adultos Privados de Liberdade que este estudo buscou abordar.

O prazer relatado pelos docentes foi ter a sua atividade profissional reconhecida pelos alunos, de ser respeitado em sala de aula e o interesse demonstrado por estes. Mesmo que a educação seja procurada em função da remição da pena (cada 12 horas de estudo diminui um dia de pena) há um aproveitamento desse espaço de ensino e aprendizagem.

Já o que causa sofrimento é a grande rotatividade de alunos, que faz com que eles não consigam avançar no conteúdo. A questão da organização do trabalho com relação à equipe de segurança nos estabelecimentos prisionais gera diferentes sentimentos. Ora se sentem engessados com relação a não terem autonomia para realizar algumas atividades que tornam as aulas mais interessantes como recursos materiais, audiovisuais e a necessidade de acompanhamento durante os deslocamentos dos alunos privados de liberdade até a sala de aula, ora se sentem cuidados e/ou em segurança devido a desses profissionais.

A psicodinâmica do trabalho tem se apoiado em dois pontos principais: as relações sociais do trabalho e do sofrimento no trabalho. Dessa forma, a escuta de trabalhadores proporciona um espaço privilegiado para que seja possível pensar o mundo do trabalho, e assim ressignificar o sofrimento (Perez, 2012) identificando também o trabalho prescrito e o trabalho real do docente de Educação de Jovens e Adultos Privados de Liberdade.

É importante reiterar que se trata de pessoas privadas de liberdade, mas que não são privadas de direito, uma vez que em nossos país, a saúde e a educação são direitos universais. Por outro lado, as pessoas que trabalham nesse contexto de privação de liberdade acabam por sofrer as consequências de toda a organização do sistema prisional.

\section{Referências}

Alarcão, I. (2003). Professores reflexivos em uma escola reflexiva. São Paulo: Cortez.

Assis, R. D. (2007). A realidade atual do sistema penitenciário Brasileiro. Recuperado: 26 jun. 2010. Disponível: http:// br.monografias.com/trabalhos908/a-realidade-atual/a-realidadeatual.shtml.

Baierle, T. \& Merlo, A. (2008). Saúde mental e subjetividade no trabalho de guarda municipal. Cadernos de psicologia social do trabalho, 11(1), 68-91.

Constituição da república federativa do Brasil (1988). Brasília, DF: senado federal.

Bendassolli, P. F. \& Soboll, L. Andrea P. (2011). Clínicas do Trabalho: Novas Perspectivas para compreensão do trabalho na atualidade. São Paulo: Atlas.

Dejours, C. (2003). A loucura do trabalho: estudo da psicopatologia do trabalho (5a ed.). São Paulo: Cortez.

Dejours C. (2004). Addendum: da psicopatologia à psicodinâmica do trabalho. In: Lancman S. \& Sznelwar, L.I. (Orgs) Christophe Dejours: da psicopatologia à psicodinâmica do trabalho (pp. 47104). Rio de Janeiro: Editora Fiocruz, Brasília, DF: Paralelo 15.

Dejours, C (2012) Trabalho Vivo: Sexualidade e Trabalho. Volume I e II. Brasília: Paralelo 15.

Facas, E. P., Machado, A. C. A., \& Mendes, A. M. B. (2012). A negação do saber operário no trabalho automatizante: análise psicodinâmica do trabalho de pilotos de trem de metrô do Distrito Federal. Revista Amazônica, v. IX, pp. 44-68.

Ferreira, M. C.; Mendes, A. M. (2003). Trabalho e riscos de adoecimento: o caso dos auditores-fiscais da Previdência Social brasileira. Brasília: Ler, Pensar e Agir.

Lancman, S. \& Sznelwar, L. (org.) (2011). Christophe Dejours: Da psicopatologia à psicodinâmica do trabalho. Trio de Janeiro, $3^{\mathrm{a}} \mathrm{Ed}$, Editora Fiocruz. 
Lei No 12.433, de 29 de junho de 2011. Altera a Lei no 7.210, de 11 de julho de 1984 (Lei de Execução Penal), para dispor sobre a remição de parte do tempo de execução da pena por estudo ou por trabalho. Recuperado: 1 jun. 2017. Disponível: http://www.planalto. gov.br/ccivil_03/_ato2011-2014/2011/lei/l12433.htm

Mello, D. V. \& Craidy, C. M. (2010).Educação nos Presídios no Rio Grande do Sul e características da população carcerária. Em C. M. C. (Org.), Educações em Prisões: direito e desafio (pp. 73-84). Porto Alegre: Ed UFRG.

Moreira, F. A. (2007). A política de Educação de Jovens e Adultos em Regime de Privação de Liberdade no Estado de São Paulo. Dissertação de mestrado do Programa de Pós-graduação em Educação da USP, São Paulo, SP.

OIT (Organização Internacional do Trabalho) (1984). A condição dos professores: A condição dos professores recomendação Internacional de 1966, um instrumento para a melhoria da condição dos professores. Genebra: OIT/ Unesco.

Onofre, E. M. C. (2012). Desafios Históricos na Educação Prisional Brasileira: ressignificando a formação de professores... um quê de utopia? Revista HISTEDBR On-line, Campinas, n. 47, p.205-219, set. 2012.

Penna, M. G. O. (2003). O ofício do professor: as ambigüidades do exercício da docência por monitores presos. Dissertação de Mestrado, Programa de Educação (História, Política, Sociedade), Pontifícia Universidade Católica de São Paulo, SP.

Penna, M. G. O. (2006). Exercício docente na prisão: apontamentos sobre aspectos do habitus do professor. Práxis Educativa, Ponta Grossa,v. 1, n. 2, pp. 31 - 38, jul-dez. Recuperado: 10 out. 2016. Disponível: http://www.revistas2.uepg.br/index.php/ praxiseducativa/article/viewFile/283/289
Perez, K. (2012). "Se tirar o trabalho, sobra um cantinho que a gente deixou ali”. Dissertação de Mestrado em Psicologia Social e Institucional, Universidade do Rio Grande do Sul, Porto Alegre, RS.

Portugues, M. R. (2001). Educação de Adultos Presos: possibilidades e contradições da inserção da educação escolar nos programas de reabilitação do Sistema Penal do Estado de São Paulo. Dissertação de Mestrado em Educação, Universidade de São Paulo, SP.

Rego, T. C. \& Mello, G. N. (2002). Formação de professores na América Latina e Caribe: a busca por inovação e eficiência. In: Conferência regional "O desempenho dos professores na América Latina: novas prioridades", de 10 a 12 de julho de 2002, Brasília, Brasil: UNESCO; PREAL; BID; MEC. Recuperado: 10 out. 2016. Disponível: http://www.namodemello.com.br/pdf/escritos/oficio/ maura-enviado18-06.pdf.

Santos, S. (2006). A educação escolar no sistema prisional sob a ótica de detentos. Dissertação de Mestrado em Educação: História, Política, Sociedade, Pontifícia Universidade Católica de São Paulo, São Paulo, 2002.

Scarfò, F. J. (2002). El derecho a la educación em las cárceles como garantia de la educación em derechos humanos (EDH). Revista IIDH. v. 36, $291-324$.

Silva, M. C. V. (2006). A Prática docente de EJA: o caso da Penitenciária Juiz Plácido de Souza em Caruaru. Caminhos da Utopia. Centro Paulo Freire estudos e Pesquisas. Edições Bagaço.

Tavares, G. \& Menandro, R. M. (2004). Atestado de Exclusão com Firma reconhecida: o sofrimento do presidiário brasileiro. Psicologia Ciência e Profissão, 24(2), 86-99 Recuperado: 25 abr. 2005. Disponível: http://www.revistacienciaeprofissao.org

\section{Sobre os autores}

Marcela Haupt Bessil (celahb@gmail.com)

Mestrado em Psicologia Social e Institucional pela Universidade Federal do Rio Grande do Sul. (2015). Psicóloga Voluntária do Grupo de Apoio à Prevenção da AIDS/RS, UFRGS.

\section{Alvaro Roberto Crespo Merlo (merlo@ufrgs)}

Doutor em Sociologia pela Université Paris VII. Docente da Universidade Federal do Rio Grande do Sul, atua na Faculdade de Medicina, no Programa de Pós-Graduação em Psicologia Social e Institucional da UFRGS. 
